\title{
Telemedicine Technologies for Diabetes in Pregnancy: A Systematic Review and Meta-Analysis
}

Wai-Kit Ming ${ }^{1,2}$, MPH, MD, PhD; Lucy H Mackillop ${ }^{3}$, FRCP, MA; Andrew J Farmer ${ }^{4}$, FRCGP, DM; Lise Loerup ${ }^{5}$, ME; Katy Bartlett ${ }^{3}$, RM; Jonathan C Levy ${ }^{6}$, FRCP, MD; Lionel Tarassenko ${ }^{5}$, FMedSci, FREng, CBE; Carmelo Velardo $^{5}, \mathrm{PhD}$; Yvonne Kenworthy ${ }^{1}$, RM, BSc; Jane E Hirst ${ }^{1}$, FRANZCOG, PhD

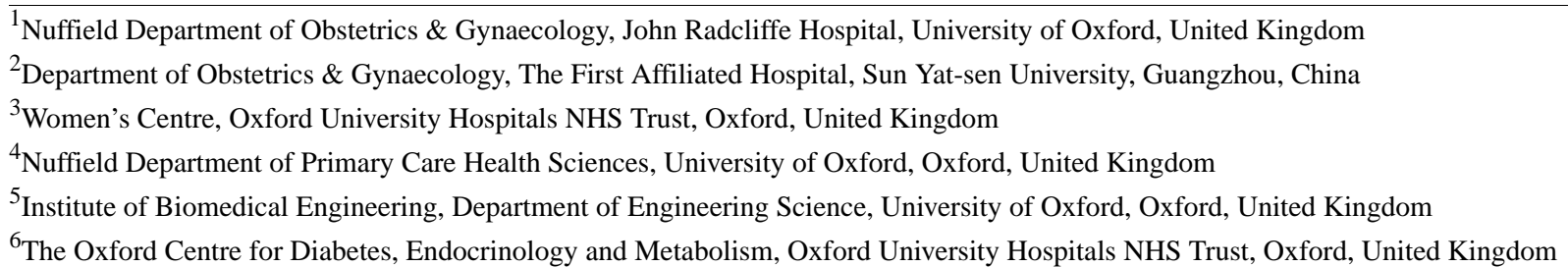

\section{Corresponding Author:}

Jane E Hirst, FRANZCOG, PhD

Nuffield Department of Obstetrics \& Gynaecology

John Radcliffe Hospital

Level 3, Women's Centre, John Radcliffe Hospital

Oxford, OX3 9DU

United Kingdom

Phone: 4401865221019

Fax: 4401865769141

Email: jane.hirst@obs-gyn.ox.ac.uk

\section{Abstract}

Background: Diabetes in pregnancy is a global problem. Technological innovations present exciting opportunities for novel approaches to improve clinical care delivery for gestational and other forms of diabetes in pregnancy.

Objective: To perform an updated and comprehensive systematic review and meta-analysis of the literature to determine whether telemedicine solutions offer any advantages compared with the standard care for women with diabetes in pregnancy.

Methods: The review was developed using the Preferred Reporting Items for Systematic Reviews and Meta-Analyses (PRISMA) framework. Randomized controlled trials (RCT) in women with diabetes in pregnancy that compared telemedicine blood glucose monitoring with the standard care were identified. Searches were performed in SCOPUS and PubMed, limited to English language publications between January 2000 and January 2016. Trials that met the eligibility criteria were scored for risk of bias using the Cochrane Collaborations Risk of Bias Tool. A meta-analysis was performed using Review Manager software version 5.3 (Nordic Cochrane Centre, Cochrane Collaboration).

Results: A total of 7 trials were identified. Meta-analysis demonstrated a modest but statistically significant improvement in $\mathrm{HbA1c}$ associated with the use of a telemedicine technology. The mean HbA1c of women using telemedicine was 5.33\% (SD 0.70 ) compared with $5.45 \%$ (SD 0.58) in the standard care group, representing a mean difference of $-0.12 \%(95 \% \mathrm{CI}-0.23 \%$ to $-0.02 \%)$. When this comparison was limited to women with gestational diabetes mellitus (GDM) only, the mean HbA1c of women using telemedicine was 5.22\% (SD 0.70) compared with 5.37\% (SD 0.61) in the standard care group, mean difference $-0.14 \%(95 \% \mathrm{CI}-0.25 \%$ to $-0.04 \%)$. There were no differences in other maternal and neonatal outcomes reported.

Conclusions: There is currently insufficient evidence that telemedicine technology is superior to standard care for women with diabetes in pregnancy; however, there was no evidence of harm. No trials were identified that assessed patient satisfaction or cost of care delivery, and it may be in these areas where these technologies may be found most valuable.

(J Med Internet Res 2016;18(11):e290) doi: 10.2196/jmir.6556

\section{KEYWORDS}

pregnancy; diabetes mellitus; telemedicine; review; meta-analysis; pregnancy in diabetics 


\section{Introduction}

Diabetes in pregnancy is a global problem and innovative solutions are required to prevent adverse outcomes in the mother and the offspring [1]. The prevalence of gestational diabetes mellitus (GDM) has increased dramatically with the International Diabetes Federation estimating that 1 in 7 pregnant women had GDM in 2015 [2,3]. The aims of clinical management, whether for women with type 1, type 2, or GDM, are to normalize maternal blood glucose to reduce complications and improve maternal and pregnancy outcomes [4]. Current evidence supports regular self-blood glucose monitoring (SBGM) up to 7 times a day, dietary and lifestyle counselling, and, frequently, hypoglycemic medications with dose titration in response to glycemic control [1,5,6]. Adequacy of glycemic control is determined by reviewing SBGM results, traditionally recorded by the woman by hand in paper diaries. The frequent need for outpatient visits to review these results as pregnancy progresses places pressure on maternity and diabetic services and is an inconvenience for pregnant women and their families.

Technological innovations present exciting opportunities for novel approaches to improve clinical care delivery for women with diabetes in pregnancy. Telemedicine (also known as telehealth) is defined as the provision of health services at a distance using a range of technologies [7]. The World Health Organization recommends telemedicine systems should be introduced where there is demand from patients [8]. With 1 in 3 people on the planet predicted to own a mobile phone by the end of 2016 [9], there is great enthusiasm among both patients and health care professionals to harness digital technologies to improve human health. In line with this, the number and sophistication of apps developed specifically for women with diabetes in pregnancy has increased [10,11]. Digital technologies in this patient group have most commonly been used to record and transmit blood glucose readings to the clinical care team between outpatient visits. This can involve either synchronous (ie, real-time) or asynchronous interactions, facilitating 2-way communication between the clinical care team and the pregnant woman [12,13]. Examples of technologies to perform this task include mobile apps, short message service (SMS), automated telephone support systems, Web-based diaries and decision-support systems, and integrated systems combining multiple elements of digital communication technologies (eg, mobile apps supported by Web platforms) [10,14-21].

Despite this enthusiasm, the benefits of telemedicine in women with diabetes in pregnancy remain uncertain [22]. Before recommending routine use and scale-up, ideally, there should be some evidence of benefit, or, at least no evidence of harm, when compared with traditional models of care. In addition to clinical benefit, telemedicine may offer advantages over standard care through improved efficiency of health care delivery, better maternal satisfaction with care [23,24], and economic savings related to fewer clinical visits [25].

The field of telemedicine is rapidly changing. We aimed to perform an updated and comprehensive systematic review and meta-analysis of the literature to determine whether, in pregnant women with any form of diabetes, telemedicine solutions offer any advantages compared with standard care. Outcomes were considered with respect to (1) maternal glycemic control, (2) pregnancy complications, (3) maternal satisfaction, and (4) costs of care.

\section{Methods}

\section{Study Design}

A research protocol was developed according to the Preferred Reporting Items for Systematic Reviews and Meta-Analyses (PRISMA) framework [26].

\section{Search Strategy}

The search strategy was developed with the advice of a professional librarian, with searches performed in SCOPUS (Medline, EMBASE, and Compendex) and PubMed to identify all relevant publications published between January 2000 and January 2016. This date restriction was selected as it was thought any telemedicine systems reported prior to this time would not be comparable with contemporary technology.

\section{Inclusion Criteria}

For the purpose of this review, any pregnant woman with a diagnosis of GDM (according to any criteria) or with preexisting type 1 diabetes or type 2 diabetes was eligible for inclusion. For this paper, telemedicine was defined as any system to monitor blood glucose remotely utilizing either fixed-line phones, mobile phones, or Internet-based systems. Databases were searched using the keywords tele*, digital*, comput*, *phone*, mobile*, app*, remote*, PDA, web*, tech*, Internet*, automat*, video*, wireless, short messag*, SMS, ehealth and e-health combined with gestational diabetes, GDM, pregnan* diabetes, pregnan* DM, and pregnan* gly*. These terms were combined using Boolean operators. The full search strategy for the SCOPUS and PubMed database (Textbox 1) was complemented with another approach involving the review of reference lists of retrieved trials. We limited our search to RCT.

\section{Exclusion Criteria}

Trials were excluded if they were quasi- or non-randomized, conducted in women where pregnancy status was not clearly stated, or the comparator group was another digital technology (rather than standard care). For practical reasons, the search was limited to English language publications. 
Textbox 1. Search terms used to identify articles related to telemedicine or related technology used in gestational diabetes.

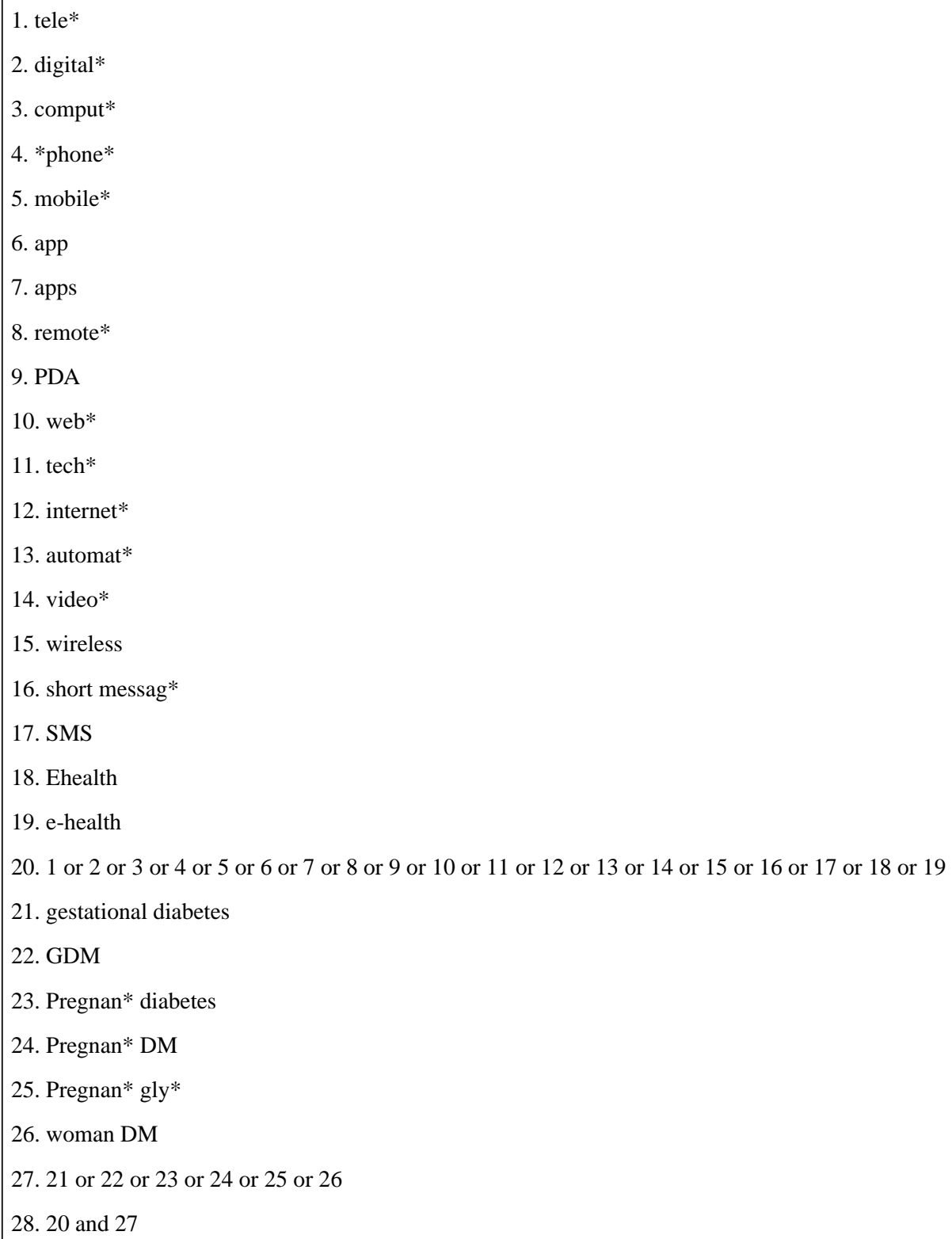

\section{Study Selection Process}

One of the authors (W Ming) independently screened the titles and abstracts of identified citations for potential eligibility. Two authors (W Ming and J Hirst) independently examined the full-text articles of eligible papers and extracted information about the exposures and outcomes using a predefined data extraction table.

\section{Outcomes}

The primary outcome was maternal glycemic control. Owing to the challenges in quantifying glycemic control and lack of consensus in measuring and reporting this outcome in pregnancy, we chose to define glycemic control with respect to mean blood glucose during pregnancy monitoring (total, fasting, or 1-h or 2-h post-prandial blood, expressed in $\mathrm{mmol} / \mathrm{L}$ ), and final recorded $\mathrm{HbA} 1 \mathrm{c}$ in pregnancy (reported as both \% and $\mathrm{mmol} / \mathrm{mol})$.

Secondary outcomes included insulin usage (ie, the final dose of insulin in units), mode of delivery (vaginal delivery or cesarean section), and the proportion of cases of shoulder dystocia at birth. As poor glycemic control in pregnancy is associated with increased fetal size, we also compared differences in fetal size as defined by mean birth weight, rates of macrosomia (defined as birth weight $>4000 \mathrm{~g}$ ), and the proportion of babies that were large for gestational age (LGA; defined as birth weight for gestational age and gender $>90$ th percentile using local references). Neonatal outcomes were also assessed including the need for any neonatal intensive care unit (NICU) admission, preterm birth <37 completed weeks, and neonatal hypoglycemia (defined as hypoglycemia requiring medical treatment; Multimedia Appendix 1).

\section{Data Extraction and Quality Assessment}

Information on trial design and data on the primary and secondary outcomes were extracted by 2 reviewers, independently, using a predesigned Excel spreadsheet. Each 
trial was scored for the risk of bias using the Cochrane Collaboration Risk of Bias Tool. A third reviewer was available if there was a difference in opinion in interpreting the risk of bias.

\section{Data Synthesis and Analysis}

Meta-analysis was performed using Review Manager software (Version 5.3). Given that different technologies were assessed and the definitions of diabetes and standard care varied between the trials, we anticipated a large amount of heterogeneity in the results. Therefore, we applied random effects models with the $\mathrm{I}^{2}$ statistic reported. $\mathrm{I}^{2}$ values $>50 \%$ are considered to indicate substantial heterogeneity. Results are presented as the differences in risk ratios for binary outcomes and mean difference for continuous variables, with $95 \%$ CI. Results were stratified by the diabetes type if more than 1 trial was available.
For outcomes reported in only 1 trial or unable to be combined across trials, a narrative synthesis was presented.

\section{Results}

\section{Study Selection and Study Characteristics}

The search and screening strategy is shown in Figure 1. Seven of the 54 trials selected for full-text review met the inclusion criteria, involving 579 women: 496 women with GDM (5 trials) [16,21,27-29] and 83 with type 1 diabetes (3 trials) [15,21,30]. The trial of Dalfra et al presented results separately for women with GDM and type 1 diabetes; thus, for analysis we present this trial stratified by diabetes type [21]. All trials were small in size, ranging from 19 to 203 women with a median of 57 (interquartile range 32-85). The 7 trials were all conducted in high-income countries (5 in Europe and 2 in North America). See Multimedia Appendix 1.

Figure 1. Study selection. RTC: randomized controlled trial; GDM: gestational diabetes mellitus; T1 DM: type 1 diabetes mellitus; T2 DM: type 2 diabetes mellitus.

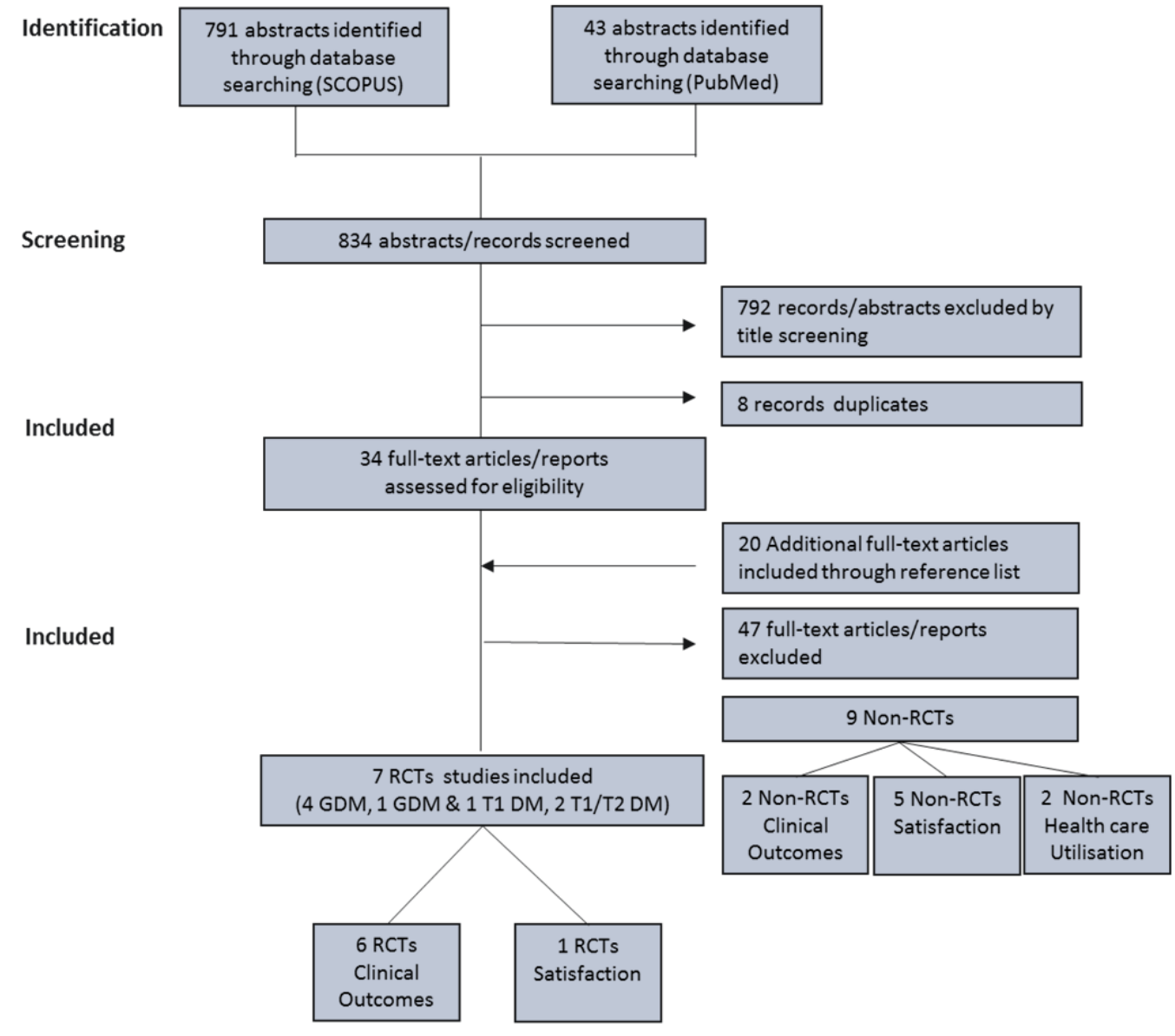

\section{Modes of Communication and Type of Intervention}

Technologies assessed were modem transmission of blood glucose readings to a central hospital computer [15], websites accessible to patients and health care professionals $[17,18]$, a telephone system that translated blood glucose readings into audio tones to transmit them to a computer database [21], SMS transmissions of blood glucose readings to a central database [19], and a telemedicine hub located in the woman's home, which transmitted data every week to a clinical team through the Internet [16]. All trials described the comparison groups as receiving "routine care." However, this ranged from information given only about the method of blood glucose monitoring (ie, paper log books), to detailed descriptions of care pathways. The frequency of clinic visits differed between the trials, ranging from weekly to monthly visits.

\section{Methodological Quality Assessment}

Overall, all the trials displayed potential sources of methodological bias (Figures 2 and 3). Owing to the nature of 
the intervention, blinding of participants and health care providers was not possible and therefore we elected to not include this as part of the risk of bias assessment. Considering the method of randomization, 2 trials were found to be at low risk of bias, reporting the use of computerized stratified block randomization $[15,16]$. The remainder either used methods that were likely to be of high risk of bias, or did not report this component. Only 1 trial reported use of an adequate allocation concealment method [17]. Two trials gave a full description of participants and losses to follow-up during their trial $[16,17]$. Other trials reported losses to follow-up or postrandomization

Figure 2. Distribution of bias in the included trials. exclusions, which potentially may have affected the results. Reporting bias is the selective reporting of some outcomes but not others depending on the nature and direction of the results [31]. Only 1 included trial was judged to be at low risk of reporting bias [17], reporting a comprehensive range of glucose and clinical outcomes.

All the identified trials addressed clinical outcomes. Only 1 trial also reported maternal satisfaction; however, no comparative statistics were given between the intervention and the control groups. No trial presented any data on health economic outcomes.

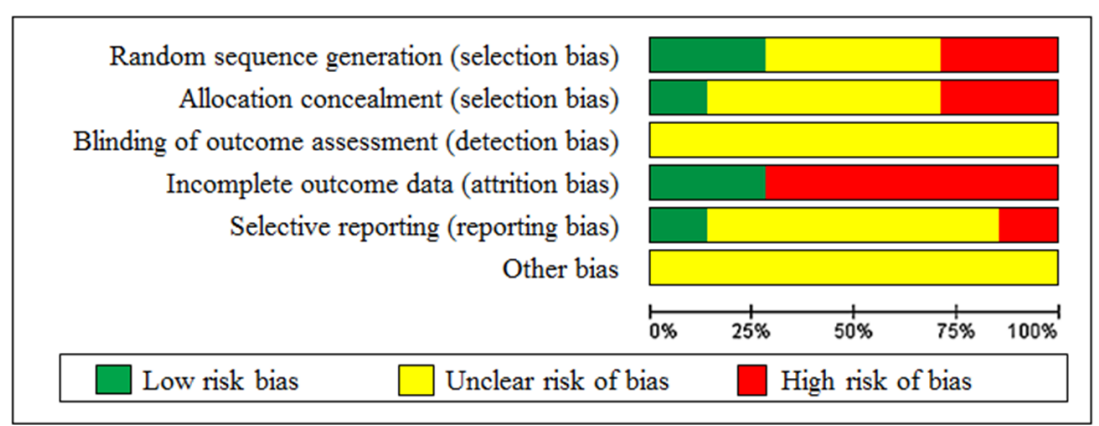

Key: Green = "yes" (low risk of bias). Red = "no" (high risk of bias). Yellow = "unclear" (bias-related information is not clear or bias cannot be determined)

Figure 3. Risk of bias in the included trials.

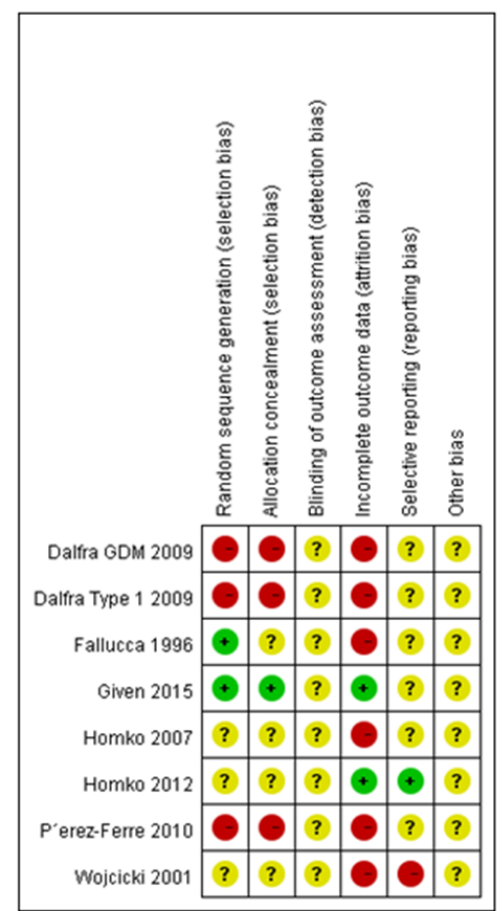

Key: Green $=$ "yes" (low risk of bias). Red $=$ "no" (high risk of bias). Yellow = "unclear" (bias-related information is not clear or bias cannot be determined).

\section{Maternal Glycemic Control}

HbA1c was the most commonly reported glycemic outcome in 5 trials [21,28-30]. Meta-analysis demonstrated a modest, but statistically significant, improvement in $\mathrm{HbA} 1 \mathrm{c}$ associated with the use of a telemedicine. The mean HbA1c of women using telemedicine was $5.33 \%$ (SD 0.70) compared with $5.45 \%$ (SD $0.58)$ in the standard care group, representing a mean difference of $-0.12 \%$ (95\% CI $-0.23 \%$ to $-0.02 \%$ ). When this comparison was limited to the 4 trials of women with GDM only, the 
difference was slightly greater [21,28,29]. The mean HbA1c of women with GDM using telemedicine was 5.23\% (SD 0.70) compared with $5.37 \%$ (SD 0.61) in the standard care group, mean difference $-0.14 \%$ (95\% CI $-0.25 \%$ to $-0.04 \%$ ). Three trials (175 women: 143 GDM and 32 type 1) compared the overall mean blood glucose levels between the intervention (telemedicine) and control (standard care) groups [27,28,30]. Meta-analysis of these trials demonstrated no evidence of difference in mean blood glucose levels; however, this was in keeping with the lack of difference in HbAlc also observed in these individual trials (Figure 4). Two of these trials reported differences between fasting and $2 \mathrm{~h}$ postprandial blood glucose, however, no significant difference was demonstrated between the groups $[15,28]$. One trial in women with type 1 diabetes reported the mean units of insulin used in each group [15]. For these 19 women, the telemedicine group used a greater total dose of insulin compared with standard care, 54 units (SD 7 units) and 36 units (SD 6 units), respectively.

Figure 4. Forest plot showing the pooled HbA1c and blood glucose level (telemedicine vs control group).

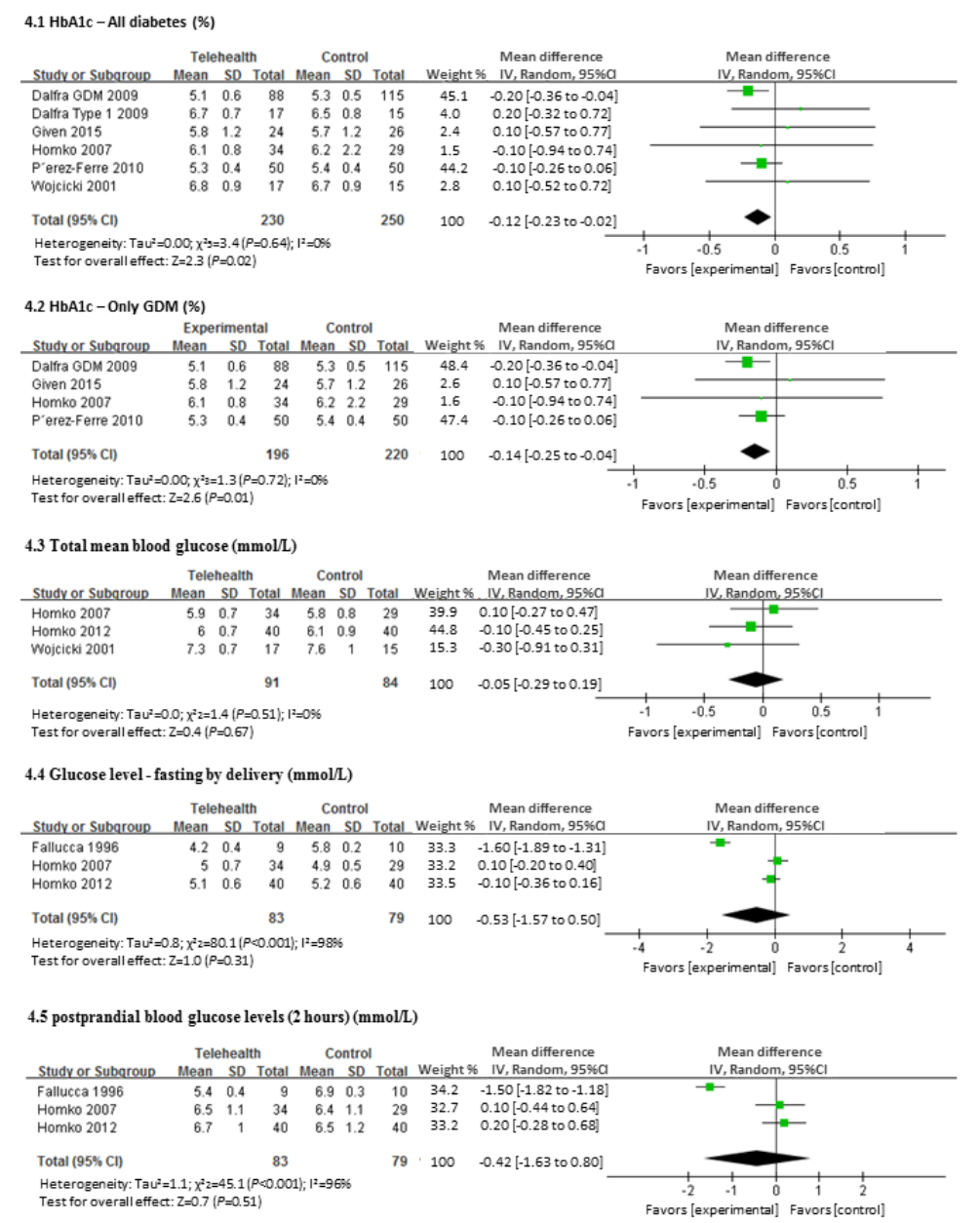

\section{Maternal and Neonatal Clinical Outcomes}

Maternal outcomes were reported variously across the trials. A total of 4 trials (148 women using telemedicine and 145 controls) reported differences between rates of pregnancy-induced hypertension or preeclampsia [27-29]. In these trials, $7.5 \%$ of women overall had either of these conditions; however, there was no difference in the risk ratio between the telemedicine or control groups (Figure 5). When considering the mode of delivery, rates of Cesarean section were high in both the groups $(50.0 \%$ in the telemedicine and $45.0 \%$ in the control) with no difference in the risk ratio. Only 2 trials (150 women) reported shoulder dystocia [29], however, with only 1 case of shoulder dystocia meta-analysis was not possible.

There was no significant difference between the groups with respect to mean birth weight. For the telemedicine group this was $3363 \mathrm{~g}$ (SD $115 \mathrm{~g}$ ) and for the standard care group it was $3302 \mathrm{~g}$ (SD $121 \mathrm{~g}$ ), with the mean gestational age at delivery of 37.9 weeks (SD 1.39 and 1.70) weeks in both groups (Figure $6)$. In the 2 trials that reported rates of macrosomia, there was no significant difference between the 2 groups, with an overall rate of $46 \%$ (129 cases and 159 controls, including 32 type 1 diabetic women) [21]. Three trials reported LGA as an outcome (124 women using telemedicine, and 119 with standard care) [27-29]. The overall prevalence of LGA in these 3 trials was $14.4 \%$, with no difference demonstrated between the 2 groups.

There were 40 babies of 193 (20.7\%) that were admitted to the NICU, however, this proportion was not significantly different between the 2 groups (Figure 7) [27,28]. Four trials reported the proportion of babies treated for neonatal hypoglycemia [27-29]. Overall, although $18.0 \%$ (18/100) of babies were treated 
for hypoglycemia, there was no evidence of differences between the intervention and control groups.

Figure 5. Forest plot showing the pooled clinical parameter-maternal outcomes (telemedicine vs control group).

5.1 Pregnancy induced Hypertension or Preeclampsia (cases)

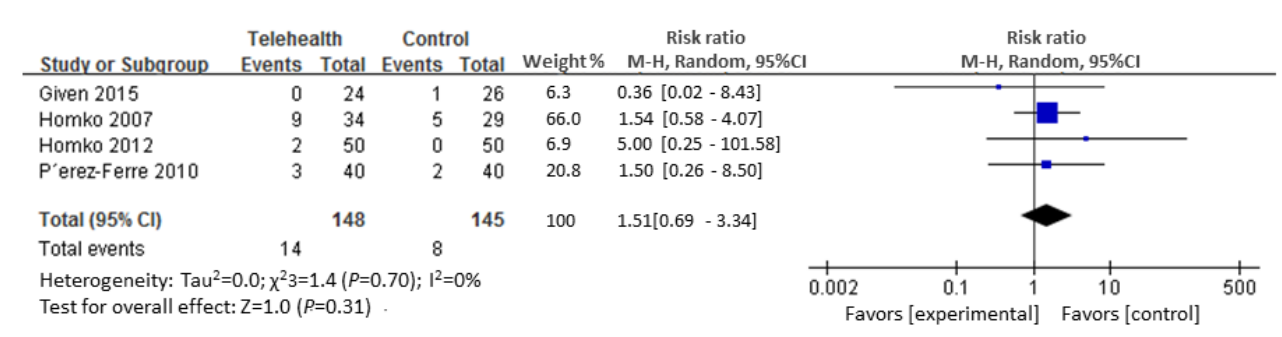

5.2 C-Section (cases)

\begin{tabular}{|c|c|c|c|c|c|c|c|c|c|c|}
\hline Study or Subqroup & $\begin{array}{l}\text { Telehea } \\
\text { Events }\end{array}$ & $\begin{array}{l}\text { alth } \\
\text { Total }\end{array}$ & $\begin{array}{c}\text { Contr } \\
\text { Events }\end{array}$ & $\begin{array}{l}\text { ol } \\
\text { Total }\end{array}$ & Weight $\%$ & $\begin{array}{c}\text { Risk ratio } \\
\text { M- } \mathrm{H}, \text { Random, } 95 \% \mathrm{Cl}\end{array}$ & & $\begin{array}{r}\text { Risk } \\
\text { M-H, Ranc }\end{array}$ & $\begin{array}{l}\text { r ratio } \\
\text { dom, } 95 \% \mathrm{Cl}\end{array}$ & \\
\hline Dalfra GDM 2009 & 34 & 88 & 61 & 115 & 23.2 & $0.73[0.53-1.00]$ & & & & \\
\hline Dalfra Type 12009 & 12 & 17 & 11 & 15 & 19.3 & $0.96[0.62-1.48]$ & & & & \\
\hline Given 2015 & 10 & 24 & 10 & 26 & 12.6 & $1.08[0.55-2.14]$ & & & & \\
\hline Homko 2007 & 22 & 34 & 10 & 29 & 15.5 & $1.88[1.07-3.28]$ & & & & \\
\hline Homko 2012 & 19 & 40 & 13 & 40 & 15.7 & $1.46[0.84-2.54]$ & & - & & \\
\hline P'erez-Ferre 2010 & 17 & 50 & 12 & 50 & 13.8 & $1.42[0.76-2.65]$ & & & & \\
\hline Total $(95 \%$ Cl) & & 253 & & 275 & 100 & $1.14[0.83-1.57]$ & & & & \\
\hline Total events & 114 & & 117 & & & & & & & \\
\hline \multirow{2}{*}{\multicolumn{7}{|c|}{$\begin{array}{l}\text { Heterogeneity: } \text { Tau }^{2}=0.1 ; \chi^{2} 5=11.8(P=0.04) ; I^{2}=58 \% \\
\text { Test for overall effect: } Z=0.8(P=0.41)\end{array}$}} & 0.5 & 1 & 2 & 5 \\
\hline & & & & & & & Favors [experime & ental] $F$ & Favors [cont & \\
\hline
\end{tabular}

Figure 6. Forest plot showing the pooled clinical parameter at birth (telemedicine vs control group).

6.1 Birth weight (g)

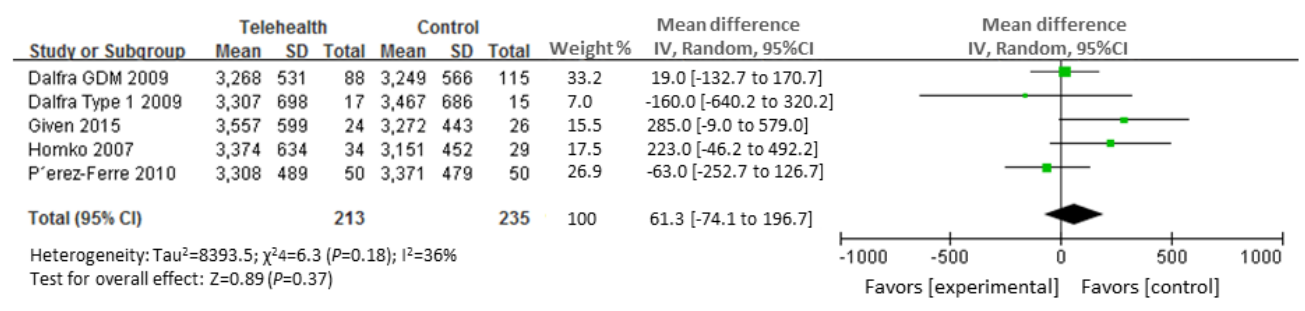

6.1 Macrosomia (cases)

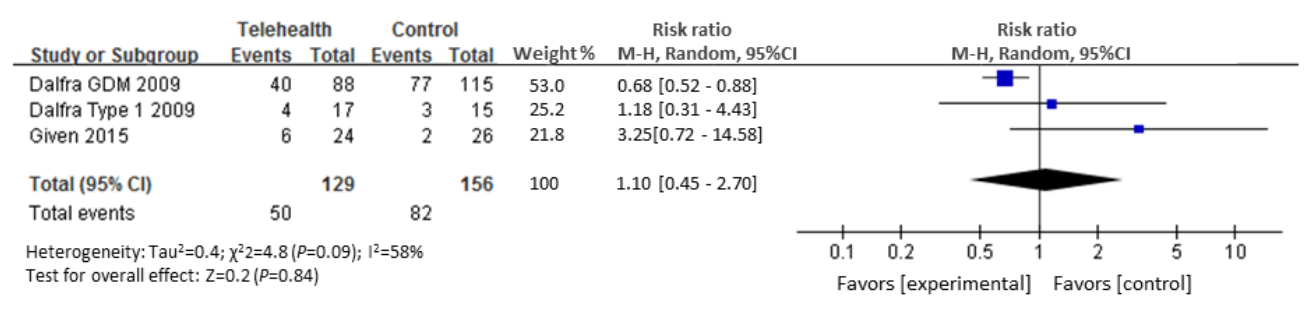

$6.3 \mathrm{LGA}>90$ th centile (cases)

\begin{tabular}{|c|c|c|c|c|c|c|c|c|c|c|c|c|}
\hline Studv or Subqroup & $\begin{array}{l}\text { Telehea } \\
\text { Events }\end{array}$ & $\begin{array}{l}\text { ilth } \\
\text { Total }\end{array}$ & $\begin{array}{l}\text { Contro } \\
\text { Events }\end{array}$ & $\begin{array}{l}\text { ol } \\
\text { Total }\end{array}$ & Weight $\%$ & $\begin{array}{c}\text { Risk ratio } \\
\text { M-H, Random, } 95 \% \mathrm{Cl} \\
\end{array}$ & & & $\begin{array}{r}\text { Risk ra } \\
\mathrm{M}-\mathrm{H}, \text { Rando } \\
\end{array}$ & $\begin{array}{l}\text { atio } \\
\text { om, } 95 \% \mathrm{Cl}\end{array}$ & & \\
\hline Homko 2007 & 9 & 34 & 3 & 29 & 28.0 & $2.56[0.76-8.57]$ & & & & $\square$ & & \\
\hline Homko 2012 & 9 & 40 & 7 & 40 & 52.3 & $1.29[0.53-3.12]$ & & & & & & \\
\hline P'erez-Ferre 2010 & 3 & 50 & 4 & 50 & 19.6 & $0.75[0.18-3.18]$ & & & & & & \\
\hline Total $(95 \% \mathrm{Cl})$ & & 124 & & 119 & 100 & $1.40[0.74-2.66]$ & & & & & & \\
\hline Total events & 21 & & 14 & & & & & & & & & \\
\hline \multirow{2}{*}{\multicolumn{7}{|c|}{$\begin{array}{l}\text { Heterogeneity: Tau }=0.0 . ; \chi^{2} 2=1.7(P=0.43) ; 1^{2}=0 \% \\
\text { Test for overall effect: } Z=1.0(P=0.30)\end{array}$}} & 0.1 & 0.2 & 0.51 & 2 & 5 & 10 \\
\hline & & & & & & & & avors [ & perimental] & Favors [c & trol] & \\
\hline
\end{tabular}


Figure 7. Forest plot showing the pooled risk of neonatal complication (telemedicine vs control group).

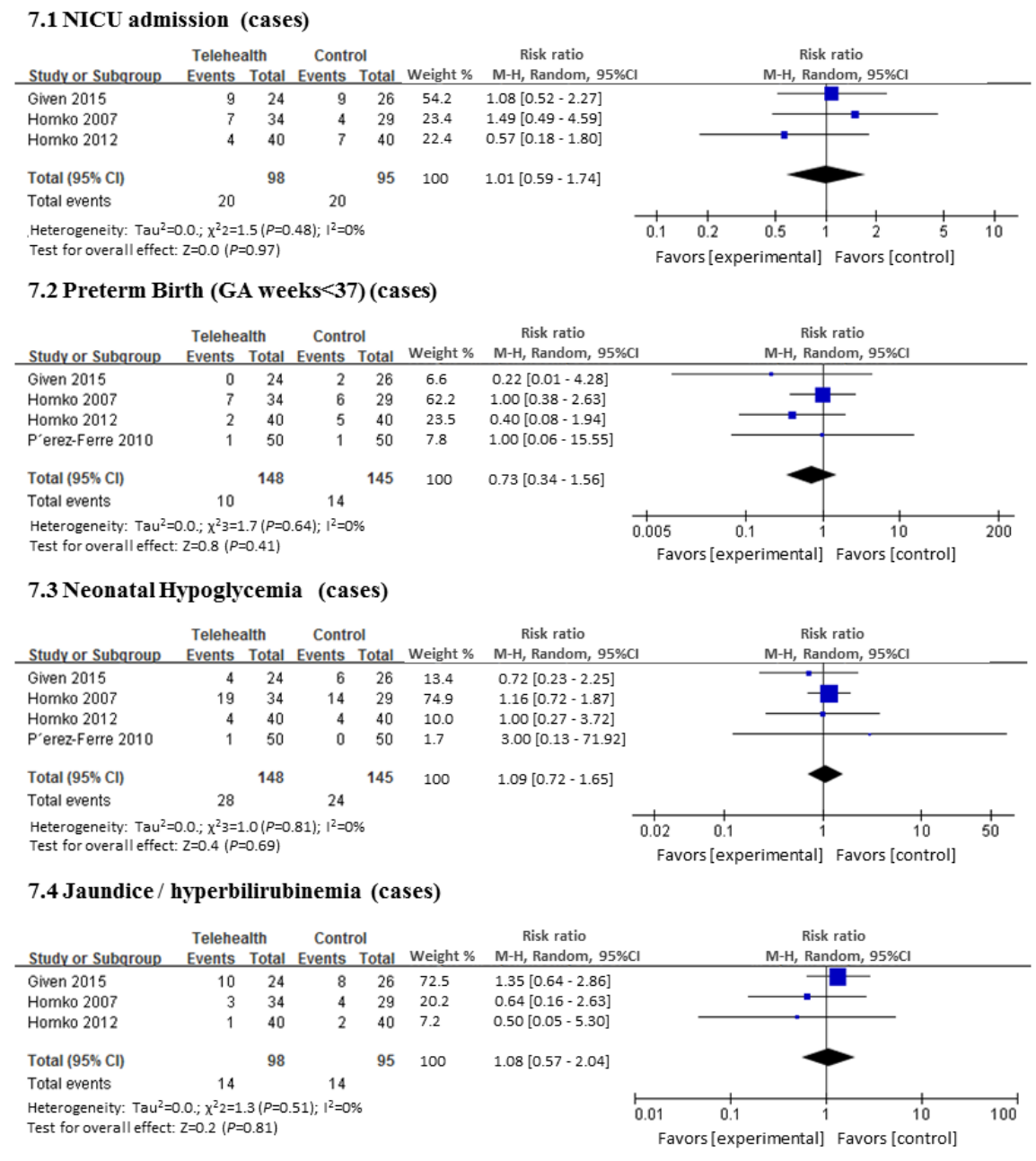

\section{Maternal Satisfaction}

One trial reported mothers' satisfaction; however, this information was only presented for the intervention group. It reported that $90 \%(17 / 19)$ of women in the telemedicine group agreed or strongly agreed that they were satisfied with the system and would use it again.

\section{Health Care Utilization}

No trials provided economic or health utilization analyses. One trial described differences in the duration of clinic visits, reporting that the telemedicine visits were $8 \mathrm{~min}$ less than those for standard care [19].

\section{Discussion}

\section{Principal Findings}

While telemedicine may offer a little advantage in terms of glycemic control in pregnant women with diabetes, there is insufficient evidence at this time to support that it has any effect on other clinical endpoints. However, the 7 trials included in our meta-analysis were all small, assessed different technologies and were deemed to contain moderate to high potential sources of methodological bias. Thus, while it is reassuring that there is no evidence of harm associated with telemedicine, it is not possible to conclude whether it offers genuine benefits.
The strengths of our review were the robust and rigorous search strategy used, identifying 3 additional trials those that had been considered in previous reviews of this topic [22,32]. We included pregnant women with all forms of diabetes, as the benefits of these technologies may not be limited to women with only GDM. There are some limitations of this review. With no agreement between the trials on the screening method and definition of GDM, or standard treatment protocols, patient groups across trials may not be precisely comparable. This is a problem for all research in GDM, and unifying clinical practice was part of the motivation behind the World Health Organization (WHO) or International Association of Diabetes in Pregnancy Study Group (IADPSG) guidelines for the diagnosis of GDM. With the rapid development of advances in communication technology, the same system has not been compared in different populations, and there has been no evidence of sustained scale-up of any of these technologies. This makes it difficult to recommend any 1 system over another. Despite these differences, as the underlying concept of remotely communicating blood glucose readings between outpatient visits was the same across these trials, therefore we deemed these trials as suitable for meta-analysis. A further limitation of this review is that some of the outcomes examined, such as Cesarean section rates, gestational age at delivery, and admission to the NICU, may be more influenced by local practice, rather than being directly influenced by the intervention itself. The recent 
initiative by the IADPSG to attempt to standardize reporting and outcomes in diabetic pregnancy research could be a valuable advance in the future to ensure results are more comparable in this area research [33].

As stated, the sample sizes in all these trials was small. In GDM research, trials powered to detect a difference in important adverse clinical outcomes generally need to recruit around 1000 women [34,35]. Even with meta-analysis therefore, this analysis is likely to be underpowered to detect any effect on severe less common perinatal outcomes, such as shoulder dystocia and death.

Two earlier reviews on telemedicine in the management of the pregnancy with GDM have previously been published [22,32]. Mastrogiannis et al presented a narrative synthesis of trials published on telemedicine for diabetic pregnancies published before 2012. The authors concluded that telemedicine solutions for pregnant women with diabetes could reduce patient visits and potentially improve quality of life, without increasing the risk of the maternal and neonatal outcomes. Rasekaba et al presented a meta-analysis limited to women with only GDM. They identified 4 publications from 1990 to 2013 and concluded that there was insufficient evidence to support clinical benefit. Other possible benefits, such as economic savings or patient satisfaction, were not assessed. Rasekaba concluded that there was a non-significant trend to better the HbAlc of the telemedicine group [22]. By identifying and including additional trials, we have been able to demonstrate that this difference is significant both for all women with any form of diabetes in pregnancy, and those with GDM only. However, this outcome should be interpreted with caution; iron deficiency and the increased turnover of red blood cells in pregnancy can make HbAlc a less sensitive indicator of glycemic control in pregnancy [36]. Similar to our findings, Rasekaba et al did not find any difference in other clinical outcomes [22].

Whereas there were no randomized trials that assessed maternal satisfaction, there is evidence from nonrandomized trials that telemedicine is associated with high levels of satisfaction. [24] Women report these systems to be convenient to use, particularly if they live far from the hospital, have other caring responsibilities, or need to take time off work to attend appointments [1,24,37]. These observations have only been assessed in women with GDM, and ideally should be confirmed for women with type 1 and 2 diabetes among whom a reduction in clinic visits may not be desirable, however greater supervision and support may be associated with benefits in itself.

There is limited evidence that fewer outpatient visits may be needed for women with GDM using telemedicine systems [38]. We did not identify any formal health economic evaluations of telemedicine systems for gestational diabetes. In nondiabetic pregnant women, an economic analysis was conducted for a telemonitoring system designed for high-risk pregnant women in the Netherlands [39]. The system evaluated involved self-measurement and transmission of blood pressure, temperature, cardiotocography (CTG), and weight and urine albumin to a clinical care provider. This system demonstrated a cost-benefit system when compared with in-patient care. However, as this system did not measure blood glucose, and as admission for blood glucose monitoring is rare in developed countries, results cannot be extrapolated to the diabetic pregnant population. In the nonpregnant population 1 meta-analysis has assessed the economic impact of telemedicine for adults with type 2 diabetes $[39,40]$. The authors identified 2 papers that assessed cost-effectiveness. However, owing to small numbers and lack of consistency in the reporting of costs and outcomes, no conclusion could be drawn. A comprehensive cost analysis of direct and indirect costs is ideally needed before widespread adoption of these systems into clinical care [41].

\section{Conclusions}

There is insufficient evidence to conclude that for women with diabetes in pregnancy, telemedicine systems produce superior clinical outcomes when compared with standard care. The reasons for this may be due to the existing studies being underpowered to detect small effect sizes and heterogeneity in the available technologies and methods by which they have been assessed. It may be however that the main benefits of these technologies are in improving maternal satisfaction and streamlining clinical care delivery. High-quality research is still needed to determine the efficacy, satisfaction, burden to pregnant women and to the health care system, and economic impact of telemedicine systems for this patient group.

\section{Acknowledgments}

The authors acknowledge support from the Oxford NIHR Biomedical Research Centre. All authors had full access to all data of this study. The corresponding author (J Hirst) had the final for the responsibility for decision for publication.

\section{Conflicts of Interest}

None declared.

\section{Multimedia Appendix 1}

Study characteristics.

[PDF File (Adobe PDF File), 41KB-Multimedia Appendix 1]

\section{References}

1. Kelley KW, Carroll DG, Meyer A. A review of current treatment strategies for gestational diabetes mellitus. Drugs Context 2015;4:212282 [FREE Full text] [doi: 10.7573/dic.212282] [Medline: 26213555] 
2. IDF. IDF Diabetes Atlas reveals high burden of hyperglycaemia in pregnancy. 2014. URL: http://www.idf.org/diabetesvoice/ issue-1-2014/idf-diabetes-atlas [accessed 2016-10-27] [WebCite Cache ID 61Z6mfibF]

3. Mulla WR, Henry TQ, Homko CJ. Gestational diabetes screening after HAPO: has anything changed? Curr Diab Rep 2010 Jun;10(3):224-228. [doi: 10.1007/s11892-010-0109-3] [Medline: 20425586]

4. Tieu J, McPhee AJ, Crowther CA, Middleton P. Screening and subsequent management for gestational diabetes for improving maternal and infant health. Cochrane Database Syst Rev 2014(2):CD007222. [doi: 10.1002/14651858.CD007222.pub3] [Medline: 24515533]

5. Balsells M, García-Patterson A, Solà I, Roqué M, Gich I, Corcoy R. Glibenclamide, metformin, and insulin for the treatment of gestational diabetes: a systematic review and meta-analysis. BMJ 2015;350:h 102 [FREE Full text] [Medline: 25609400]

6. Walker JD. NICE guidance on diabetes in pregnancy: management of diabetes and its complications from preconception to the postnatal period. NICE clinical guideline 63. London, March 2008. Diabet Med 2008 Sep;25(9):1025-1027. [doi: 10.1111/j.1464-5491.2008.02532.x] [Medline: 19183306$]$

7. The Knowledge Network. Telehealth. Health Informatics Scotland. 2016. URL: http://www.knowledge.scot.nhs.uk/his/ new-to-health-informatics/telehealth.aspx [accessed 2016-10-27] [WebCite Cache ID 61Z7Snrjc]

8. Stroetmann K, Kubitschke L, Robinson S, Stroetmann V, Cullen K, McDaid D. How can telehealth help in the provision of integrated care?: World Health Organization; 2010:1997-8073.

9. Statista. Number of smartphone users worldwide from 2014-2019. 2016. URL: https://www.statista.com/statistics/330695/ number-of-smartphone-users-worldwide/ [accessed 2016-10-27] [WebCite Cache ID 61Z7c1j2C]

10. Carral F, Ayala Mdel C, Fernández JJ, González C, Piñero A, García G, et al. Web-based telemedicine system is useful for monitoring glucose control in pregnant women with diabetes. Diabetes Technol Ther 2015 May; 17(5):349-354. [doi: 10.1089/dia.2014.0223] [Medline: 25629547]

11. Bashshur RL, Shannon GW, Smith BR, Woodward MA. The empirical evidence for the telemedicine intervention in diabetes management. Telemed J E Health 2015 May;21(5):321-354 [FREE Full text] [doi: 10.1089/tmj.2015.0029] [Medline: 25806910]

12. Allely EB. Synchronous and asynchronous telemedicine. J Med Syst 1995 Jun;19(3):207-212. [Medline: 7643019]

13. Whitten PS, Mair FS, Haycox A, May CR, Williams TL, Hellmich S. Systematic review of cost effectiveness studies of telemedicine interventions. BMJ 2002 Jun 15;324(7351):1434-1437 [FREE Full text] [Medline: 12065269]

14. Mackillop L, Loerup L, Bartlett K, Farmer A, Gibson OJ, Hirst JE, et al. Development of a real-time smartphone solution for the management of women with or at high risk of gestational diabetes. J Diabetes Sci Technol 2014 Nov;8(6):1105-1114 [FREE Full text] [doi: 10.1177/1932296814542271] [Medline: 25004915]

15. Fallucca F, DiBiase N, Sabbatini A, Borrello E, Sciullo E, Napoli A. Telemedicine in the treatment of diabetic pregnancy. Practical Diabetes Int 1996;13(4):115-118.

16. Given JE, Bunting BP, O'Kane MJ, Dunne F, Coates VE. Tele-Mum: a feasibility study for a randomized controlled trial exploring the potential for telemedicine in the diabetes care of those with gestational diabetes. Diabetes Technol Ther 2015 Dec;17(12):880-888. [doi: 10.1089/dia.2015.0147] [Medline: 26394017]

17. Homko CJ, Deeb LC, Rohrbacher K, Mulla W, Mastrogiannis D, Gaughan J, et al. Impact of a telemedicine system with automated reminders on outcomes in women with gestational diabetes mellitus. Diabetes Technol Ther 2012 Jul;14(7):624-629 [FREE Full text] [doi: 10.1089/dia.2012.0010] [Medline: 22512287]

18. Homko CJ, Santamore WP, Whiteman V, Bower M, Berger P, Geifman-Holtzman O, et al. Use of an Internet-based telemedicine system to manage underserved women with gestational diabetes mellitus. Diabetes Technol Ther 2007 Jun;9(3):297-306. [doi: 10.1089/dia.2006.0034] [Medline: 17561800]

19. Pérez-Ferre N, Galindo M, Fernández MD, Velasco V, Runkle I, de la Cruz MJ, et al. The outcomes of gestational diabetes mellitus after a telecare approach are not inferior to traditional outpatient clinic visits. Int J Endocrinol 2010;2010:386941 [FREE Full text] [doi: 10.1155/2010/386941] [Medline: 20628517]

20. Wojcicki JM, Ladyzynski P, Krzymien J, Jozwicka E, Blachowicz J, Janczewska E, et al. What we can really expect from telemedicine in intensive diabetes treatment: results from 3-year study on type 1 pregnant diabetic women. Diabetes Technol Ther 2001;3(4):581-589. [doi: 10.1089/15209150152811207] [Medline: 11911170]

21. Dalfrà MG, Nicolucci A, Lapolla A, TISG. The effect of telemedicine on outcome and quality of life in pregnant women with diabetes. J Telemed Telecare 2009;15(5):238-242. [doi: 10.1258/jtt.2009.081213] [Medline: 19590029]

22. Rasekaba TM, Furler J, Blackberry I, Tacey M, Gray K, Lim K. Telemedicine interventions for gestational diabetes mellitus: a systematic review and meta-analysis. Diabetes Res Clin Pract 2015 Oct;110(1):1-9. [doi: 10.1016/j.diabres.2015.07.007] [Medline: 26264410]

23. Mackillop L, Loerup L, Bartlett K, Farmer A, Gibson OJ, Hirst JE, et al. Development of a real-time smartphone solution for the management of women with or at high risk of gestational diabetes. J Diabetes Sci Technol 2014 Nov;8(6):1105-1114 [FREE Full text] [doi: 10.1177/1932296814542271] [Medline: 25004915]

24. Hirst JE, Mackillop L, Loerup L, Kevat DA, Bartlett K, Gibson O, et al. Acceptability and user satisfaction of a smartphone-based, interactive blood glucose management system in women with gestational diabetes mellitus. J Diabetes Sci Technol 2015 Jan;9(1):111-115 [FREE Full text] [doi: 10.1177/1932296814556506] [Medline: 25361643] 
25. Kruger DF, White K, Galpern A, Mann K, Massirio A, McLellan M, et al. Effect of modem transmission of blood glucose data on telephone consultation time, clinic work flow, and patient satisfaction for patients with gestational diabetes mellitus. J Am Acad Nurse Pract 2003 Aug;15(8):371-375. [Medline: 14509102]

26. Liberati A, Altman DG, Tetzlaff J, Mulrow C, Gøtzsche PC, Ioannidis JP, et al. The PRISMA statement for reporting systematic reviews and meta-analyses of studies that evaluate healthcare interventions: explanation and elaboration. BMJ 2009;339:b2700 [FREE Full text] [Medline: 19622552]

27. Homko CJ, Deeb LC, Rohrbacher K, Mulla W, Mastrogiannis D, Gaughan J, et al. Impact of a telemedicine system with automated reminders on outcomes in women with gestational diabetes mellitus. Diabetes Technol Ther 2012 Jul;14(7):624-629 [FREE Full text] [doi: 10.1089/dia.2012.0010] [Medline: 22512287]

28. Homko CJ, Santamore WP, Whiteman V, Bower M, Berger P, Geifman-Holtzman O, et al. Use of an Internet-based telemedicine system to manage underserved women with gestational diabetes mellitus. Diabetes Technol Ther 2007 Jun;9(3):297-306. [doi: 10.1089/dia.2006.0034] [Medline: 17561800 ]

29. Pérez-Ferre N, Galindo M, Fernández MD, Velasco V, de la Cruz MJ, Martín P, et al. A Telemedicine system based on Internet and short message service as a new approach in the follow-up of patients with gestational diabetes. Diabetes Res Clin Pract 2010 Feb;87(2):e15-e17. [doi: 10.1016/j.diabres.2009.12.002] [Medline: 20044162]

30. Wojcicki JM, Ladyzynski P, Krzymien J, Jozwicka E, Blachowicz J, Janczewska E, et al. What we can really expect from telemedicine in intensive diabetes treatment: results from 3-year study on type 1 pregnant diabetic women. Diabetes Technol Ther 2001;3(4):581-589. [doi: 10.1089/15209150152811207] [Medline: 11911170]

31. Higgins J, Green S. Cochrane handbook for systematic reviews of interventions. The Cochrane Collaboration. 2011. URL: http://handbook.cochrane.org/ [accessed 2016-10-27] [WebCite Cache ID 61Z8gIkfO]

32. Mastrogiannis DS, Igwe E, Homko CJ. The role of telemedicine in the management of the pregnancy complicated by diabetes. Curr Diab Rep 2013 Feb;13(1):1-5. [doi: 10.1007/s11892-012-0352-x] [Medline: 23242646]

33. International Association of Diabetes in Pregnancy Study Group (IADPSG) Working Group on Outcome Definitions, Feig DS, Corcoy R, Jensen DM, Kautzky-Willer A, Nolan CJ, et al. Diabetes in pregnancy outcomes: a systematic review and proposed codification of definitions. Diabetes Metab Res Rev 2015 Oct;31(7):680-690. [doi: 10.1002/dmrr.2640] [Medline: 25663190]

34. Crowther CA, Hiller JE, Moss JR, McPhee AJ, Jeffries WS, Robinson JS, Australian Carbohydrate Intolerance Study in Pregnant Women (ACHOIS) Trial Group. Effect of treatment of gestational diabetes mellitus on pregnancy outcomes. $\mathrm{N}$ Engl J Med 2005 Jun 16;352(24):2477-2486. [doi: 10.1056/NEJMoa042973] [Medline: 15951574]

35. Rowan JA, Rush EC, Obolonkin V, Battin M, Wouldes T, Hague WM. Metformin in gestational diabetes: the offspring follow-up (MiG TOFU): body composition at 2 years of age. Diabetes Care 2011 Oct;34(10):2279-2284 [FREE Full text] [doi: 10.2337/dc11-0660] [Medline: 21949222]

36. Hughes Ruth CE, Rowan J, Florkowski CM. Is there a role for HbA1c in pregnancy? Curr Diab Rep 2016 Jan;16(1):5. [doi: 10.1007/s11892-015-0698-y] [Medline: 26739347]

37. Saddik B, Al-Dulaijan N. Diabetic patients' willingness to use tele-technology to manage their disease: a descriptive study. Online J Public Health Inform 2015 May;7(2):e214 [FREE Full text] [doi: 10.5210/ojphi.v7i2.6011] [Medline: 26284148]

38. Bashshur RL, Shannon GW, Smith BR, Woodward MA. The empirical evidence for the telemedicine intervention in diabetes management. Telemed J E Health 2015 May;21(5):321-354 [FREE Full text] [doi: 10.1089/tmj.2015.0029] [Medline: 25806910]

39. Buysse H, De MG, Van MG, Baert E, Thienpont G, Temmerman M. Cost-effectiveness of telemonitoring for high-risk pregnant women. Int J Med Inform 2008 Jul;77(7):470-476. [doi: 10.1016/j.ijmedinf.2007.08.009] [Medline: 17923433]

40. Zhai Y, Zhu W, Cai Y, Sun D, Zhao J. Clinical- and cost-effectiveness of telemedicine in type 2 diabetes mellitus: a systematic review and meta-analysis. Medicine (Baltimore) 2014 Dec;93(28):e312 [FREE Full text] [doi: 10.1097/MD.0000000000000312] [Medline: 25526482]

41. Mackillop LH, Bartlett K, Birks J, Farmer AJ, Gibson OJ, Kevat DA, et al. Trial protocol to compare the efficacy of a smartphone-based blood glucose management system with standard clinic care in the gestational diabetic population. BMJ Open 2016;6(3):e009702 [FREE Full text] [doi: 10.1136/bmjopen-2015-009702] [Medline: 26988348]

\section{Abbreviations}

CTG: cardiotocography

GDM: gestational diabetes mellitus

HbA1c: hemoglobin A1c

LGA: large for gestational age

NICU: neonatal intensive care unit

PRISMA: Preferred Reporting Items for Systematic Reviews and Meta-Analyses

RCT: randomized controlled trials

SBGM: self-blood glucose monitoring

SD: standard deviation 


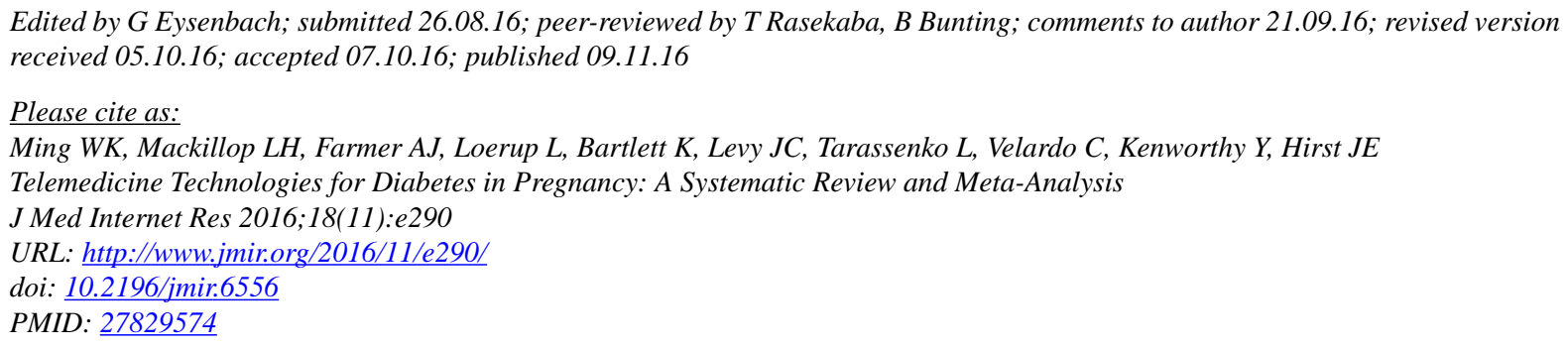

(CWai-Kit Ming, Lucy H Mackillop, Andrew J Farmer, Lise Loerup, Katy Bartlett, Jonathan C Levy, Lionel Tarassenko, Carmelo Velardo, Yvonne Kenworthy, Jane E Hirst. Originally published in the Journal of Medical Internet Research (http://www.jmir.org), 09.11.2016. This is an open-access article distributed under the terms of the Creative Commons Attribution License (http://creativecommons.org/licenses/by/2.0/), which permits unrestricted use, distribution, and reproduction in any medium, provided the original work, first published in the Journal of Medical Internet Research, is properly cited. The complete bibliographic information, a link to the original publication on http://www.jmir.org/, as well as this copyright and license information must be included. 